\title{
The European Society of Pharmacogenomics and Personalised Therapy - ESPT
}

\section{Siest G}

ESPT President, University of Lorraine, UMR Inserm U1122 "IGE-PCV", France

At the end of the Fifth Santorini Conference (October 2010) in conclusion of the round table [1] it was decided to think about the interest of having a scientific European organization able to give advice on the existing new field of pharmacogenomics. The purpose was to check the quality of the different information existing on the websites and to develop education and scientific aspects of pharmacogenomics and theranostics. A board of 6 members: Gérard Siest, Ron H.N. Van Schaik, Vangelis G. Manolopoulos, George Patrinos, Adriano Henney and Adrian Llerena has been set up and statutes under Greek law were elaborated and accepted at the first ESPT meeting and general assembly in October 2011 in Bled, Slovenia. A website (www.esptnet.eu) was also implemented.

The creation of the society was a heavy task and we had to increase the number of board members to 10 (Marc Ansari, Ingolf Cascorbi, Peter Jacobs, Adrian Llerena, Vangelis G. Manolopoulos, Janja Marc, Ron H.N. van Schaik, Gérard Siest, Maurizio Simmaco, Sophie VisvikisSiest)and to replace two members (Marja Lisa Dahl and Bohuslav Melichar) .The statutes in Greek law and the finances in Sterling pounds being managed in United Kingdom created turbulences and we decided to organize a central office in Nancy, France, in 2012 with new statutes following French rules.

We created a structure representing different categories of scientists interested in pharmacogenomics and 4 divisions were linked as described in Figure 1. Our mission is to be the leading European organization in the field of pharmacogenomics * (PGX) and Personalied Medicine ${ }^{*}$ with worldwide influence. Through leadership and innovation in science and education we will strive to enhance the scientific basis for the pharmacogenomics biomarkers recommended and then the quality of diagnosis and therapy for patients throughout the world.

\section{The Specific Aims of ESPT}

- To transcend the boundaries of single nations or single corporations, in developing the field of $\mathrm{PGx}$ and personalised medicine.

- To provide a forum for consensus, in the broadest sense, to offer a European view at the highest possible scientific and technical level, aiming to improve quality of care for the patient and maintain his health.

- To disseminate information on "best practice" at various levels of technology, clinical practice and economic development.

- To improve patients' understanding and health care on the basis of the new knowledge produced by the evolving field of PGx and Personalized Medicine.

- To inform clinicians and patients on the appropriate use of PGx information.

- To promote a vision of pharmacogenomics and personalised medicine that extends beyond traditional narrow perceptions of the field and offer an independent view to clinicians, regulators, the public and other stakeholders.

\section{ESPT Achieves these Aims by}

1. Publishing information and guidelines relating to the education of pharmacologists, clinical chemists and laboratory specialists, geneticists, clinicians, hospital pharmacists, biochemists clinical and molecular biologists and all people involved in health maintenance.

Education activities examples are displayed on our website (www. esptnet.eu ):

- Successful summerschool in Bled (2012) and in Roma (2014)

- 1 to 3 days education courses in Santorini (2012) and in Lisbon (2013).

- Creation of a web teaching platform for our members

2. Defining principles and publishing recommendations for the standardization of procedures and for interpretation of data for the benefit of health improvement.

As a first example, we published a first recommendation on generic drugs [2]. We have just decided at our last board meeting the creation of specific committees for preparing useful recommendations in the field and to propose more collaboration with our American colleagues. We will develop in 2015 such specialized committees.

- Drug transporters (created): Ingolf Cascorbi

(in Collaboration with Roche Pharma: Christoph Funk)

- Definitions personalised medicine, stratified medicine, individualized medicine, systems medicine: Maurizio Simmaco

(collaboration with Nathan I. Cherny)

- Curriculae and education for pharmacogenomics and personalised medicine: Janja Marc

Joint committee with EFLM (European Federation of Clinical Chemistry and Laboratory Medicine)

- Pharmacogenomics information for generic drugs: Vangelis Manolopoulos (with the help of Ron van Schaik, Janja Marc and Adrian Llerena) - (after a first recommendation in 2012)

*Corresponding author: Siest G, ESPT President, University of Lorraine UMR Inserm U1122 "IGE-PCV", 30 rue Lionnois, 54000 Nancy, France, Tel: +33383682170; E-mail: Gerard.siest@univ-lorraine.fr

Received January 16, 2015; Accepted February 16, 2015; Published February 20, 2015

Citation: Siest G (2015) The European Society of Pharmacogenomics and Personalised Therapy - ESPT. J Pharmacogenomics Pharmacoproteomics 6: 144. doi:10.4172/2153-0645.1000144

Copyright: (C) 2015 Siest. This is an open-access article distributed under the terms of the Creative Commons Attribution License, which permits unrestricted use, distribution, and reproduction in any medium, provided the original author and source are credited. 


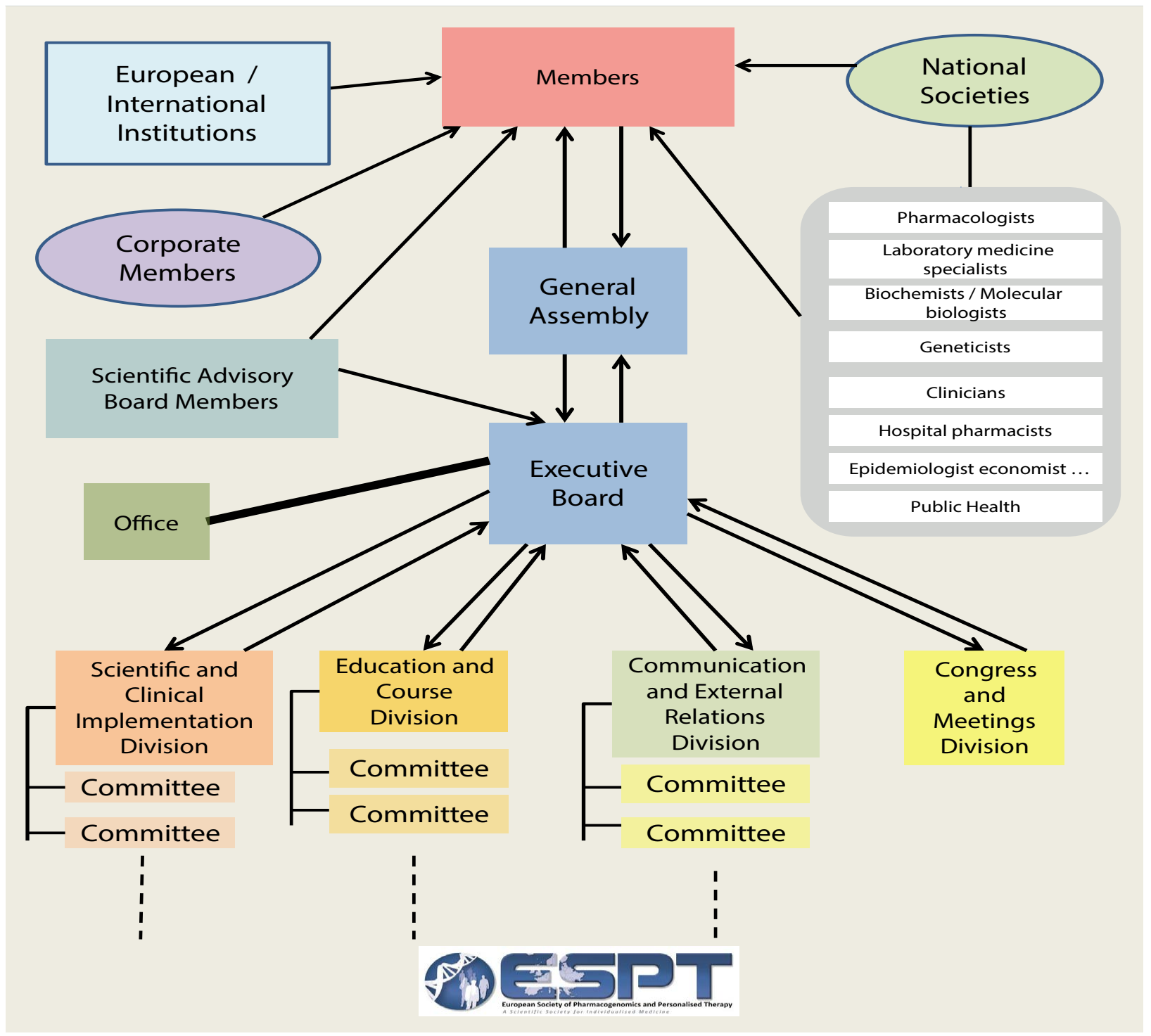

Figure 1: ESPT Organization

- Endobiotic and drug interactions: Adrian Llerena

(with the help of Vangelis Manolopoulos, Ingolf Cascorbi, Maurizio Simmaco)

\section{And later in 2016:}

- Transcription factors and pharmacogenomics: Ulrich Zanger

- Pharmacogenomics and point of care: Ron van Schaik / Candan Hizel

- Smoking /Environment and interactions with drugs: Sophie Visvikis-Siest

- Pediatric individualised treatment in oncology and hematology: Marc Ansari

All interested scientists could participate as associate members to these committees, after of course, having applied to ESPT.
3. Promoting meetings of interest to scientists through congresses, symposia and workshops in PGx and personalised medicine and by encouraging dialogues with clinicians and patients on matters of common interest.

Outside the biannual conferences in Santorini in 2010, 2012 and 2014 their report can be found on Pharmacogenomics [1,3-5] we have organized specific ESPT meetings in Bled, Lisbon and this year in Budapest. All the people interested in pharmacogenomics and personalised medicine are welcome (more information at: www. esptcongress.eu).

\section{Recent Organisation}

1. ESPT will take a major responsibility for co-ordinating the development PGX and personalised medicine on a European basis. In fulfilling this responsibility, it co-operates with many other international and regional organizations, particularly in the fields of education, research and clinical implementation. Agreement to 
cooperate have been signed or are under discussion with:

- EFLM: European Federation of Clinical Chemistry and Laboratory Medicine

- EUSPM: European Society of Predictive Medicine

- EUSTM: European Society for Translational Medicine

- ESF: European Science Foundation

- EDMA: European Diagnostic Manufacturers Association

- IMI: Innovative Medicines Initiative

- ESCP: European Society of Clinical Pharmacy

- EAPM: The Europe Alliance for Personalised Medicine

We also have special collaboration and liaison with international organization such as:

- IFCC: International Federation of Clinical Chemistry and Laboratory Medicine

- IUPHAR: International Union of Basic and Clinical Pharmacology - Pharmacogenomics Subgroup

We are also present in European research projects

- CASyM: The coordinating Action Systems Medicine. We signed and published the declaration of Rome [6].

- PerMed: Personalised Medicine 2020 and beyond Preparing Europe for leading the global way

- $\quad$ ESPT is participating in Horizon 2020 projects (VEGFproject and European Pharmacogenetics Implementation Consortium)

2. ESPT also assists and encourages the creation and organization of national societies in this domain in countries where these do not yet exist, and establishes and maintains contact with individual scientists in parts of the world where there is no professional body specifically concerned with PGX and personalised health and medicine.

We currently have 8 national linkage (Italy, Turkey, Greece, Hungary, Spain, Serbia, France, Israel) and we are in negotiation with 8 others. The criteria for becoming a national society are:

- Shall be a National Society or Network engaged in Pharmacogenomics and Personalised Medicine

- Will be the official representative of ESPT in the country

- Could organize ESPT meetings under ESPT guidance

- All members will receive information by mail or via ESPT web page

3. Simultaneously, ESPT decided to reinforce its scientific image through stronger linkage to scientific research groups.

The Research groups represent one or two research domains important for Pharmacogenomics and Personalised Medicine development:

- The group is constituted of a leader, who has to be ESPT full member and 10-30 associate members.

- $\quad$ All members have full access to all ESPT activities (Restricted area on the ESPT web site (Drug Metabolism and Drug Interaction "DMDI", teaching platform) and Reductions for courses, schools and meetings)

- The members particularly the young members will be strongly associated with the scientific activities of ESPT (Annual meetings).

- They could participate and propose new committees. This strategy will support also dynamically the career of young co-workers.

- The group will be put with the best possible visibility on our Web site and in documents. The activities of the research group will be described shortly on the web with the updated publications of the members

4. Another group of members that is very important for ESPT is the Corporate Members group

- We currently have 23 corporate members representing:

$\checkmark \quad$ Biotechnological companies

- Bühlmann Laboratories

- Randox

- $\quad$ Roche Diagnostics

- Laboratoires réunis

- Thermo Fisher Scientific

- Luminex

- Alacris

- Siemens

- $\quad$ EuroEspes S.A

- Vela Diagnostics

- Stabiligen

$\checkmark \quad$ Pharmaceutical industries

- Transgene

- Sanofi Aventis

- GSK

- $\quad$ Roche Pharma

- Galderma

- Teva

- Novartis

- Ipsen

$\checkmark \quad$ IT technologies

- Degruyter

- Biobase International

- Genomatix

- Munoz-Galeano System Integration

\section{The Benefits of Corporate Memberships in ESPT}

- Being directly involved with the leading European organization promoting contributions to Pharmacogenomics and Personalised medicine.

- Being able to hold key positions in ESPT Divisions, 
committees and influence decision making processes.

- $\quad$ Being able to propose new ESPT Working Groups and Committees and to delegate associate members to these workgroups.

- Being able to elect the Corporate Representative to the ESPT Board.

- $\quad$ Receiving all documents and publications of the ESPT.

- Publication of scientific documents and presentation of company tools in ESPT Official Journal: Drug Metabolism and Personalised Therapy (DMPT) and others we have in contact.

- Being able to submit formal comments to ESPT recommendations.

- Being able to sponsor awards, conferences, satellite symposia and various educational activities.

- Having their logo and short description of the company on ESPT website.

- Being able to use the ESPT logo to identify the company as an ESPT sponsor.

- Having access to numerous promotional opportunities.

Congresses.
We will be happy to have new corporate members. In summary, I am pleased to give you such condensed information on our European scientific organization. We wish to have more members from all the different disciplines involved in pharmacogenomics, personalised therapy and individualised medicine.

\section{References}

1. Manolopoulos VG, Dechairo B, Huriez A, Kühn A, Llerena A, et al. (2011) Pharmacogenomics and personalized medicine in clinical practice. Pharmacogenomics 12: 597-610.

2. Siest G (2012) Need for pharmacogenomics information also for generic medications: Recommendation of the European Society of pharmacogenomics and Theranostics (ESPT). Drug Metab Drug Interact 27: 119.

3. Siest G, Medeiros R, Melichar B, Stathopoulou M, Van Schaik RH, et al. Conference Scene: Pharmacogenomics: from cell to clinic (Part 1) Pharmacogenomics 15: 593-599.

4. Siest G, Medeiros R, Melichar B, Stathopoulou M, Van Schaik RH, et al (2014) Conference scene: pharmacogenomics: from cell to clinic (part 2) Pharmacogenomics 15: 739-744.

5. Siest G, Auffray $\mathrm{CH}$, Taniguchi $\mathrm{N}$, Ingelman Sundberg $\mathrm{M}$, Murray $\mathrm{H}$, et al. (2014) Systems Medicine, Personalized Health and Therapy.

6. Brand A, Lal JA (2012) European Best Practice Guidelines for Quality Assurance, Provision and Use of Genome-based Information and Technologies: the 2012 Declaration of Rome. Drug Metabol Drug Interact 27: 177-182. 